\title{
La política de fundación de ciudades de Constantino (306-337) ${ }^{1}$
}

\author{
Constantine's Policy of Foundation of Cities (306-337)
}

\author{
Esteban Moreno Resano*

\section{RESUMEN} \\ ABSTRACT
}

Uno de los aspectos más característicos del principado de Constantino fue la política de fundación de ciudades, o, más exactamente, la política de modificación de estatutos jurídicos de núcleos urbanos.

Aunque su fundación más famosa es Constantinopla, al menos se tiene constancia de que otras diecinueve poblaciones recibieron el estatuto de ciudad o, si ya lo tenían, un sobrenombre honorífico derivado del nombre del

emperador, de la familia imperial, o de miembros de la familia imperial. Es cierto que esta política no fue ni programática ni eficiente desde el punto de vista administrativo, pero tuvo una enorme importancia a efectos propagandísticos. En efecto, gracias a ella, Constantino se presentaba, al igual que Augusto, como un princeps ciuilis que fomentaba el ejercicio de la libertas política por parte de los ciudadanos a través de las instituciones municipales mediante la fundación de nuevas ciudades y la concesión de privilegios a las ya

existentes, $y$, al igual que Alejandro de Macedonia, como soberano conquistador que fundaba ciudades allí donde vencía.

\begin{abstract}
One of the most relavant aspects of Constantine's principate was the policy about the foundation of cities, or, even more exactly, the policy of modification of the juridical statutes of towns. Although his most famous foundation was Constantinople, there is clear evidence that, at least another nineteen towns received the statute of city or, if they had already got it, an honorific surname derived from the emperor's name, the imperial family name or the members of the imperial family. It is true that this policy was neither programmatic nor efficient from the administrative point of view, but it was very important to propagandistic effects. In fact, thanks to this policy, Constantine introduced himself, like Augustus, as a princeps ciuilis, promoting the exercise of the political libertas by the citizens through the municipal institutions by the foundation of new cities and the granting of privileges to the already existing ones, and, like Alexander of Macedon, as a conqueror sovereign founding towns where he succeeded.
\end{abstract}

1 Este trabajo forma parte del Proyecto de Investigación HUM2005-00209, dirigido por M. ${ }^{\text {a }}$ Victoria Escribano Paño y financiado por el Ministerio de Ciencia y Tecnología (Dirección General de Investigación y Tecnología). Agradezco a la Lda. C. Martínez Sierra la revisión del resumen en inglés.

* Universidad de Zaragoza. estmores@unizar.es 
PALABRAS CLAVE:

Constantino, fundación de ciudades, privilegios, Alejandro de Macedonia, princeps ciuilis.
KEYWORDS:

Constantine, foundation of cities, privileges, Alexander of Macedon, princeps ciuilis.

Aunque la Antigüedad tardía ha sido tradicionalmente considerada una época de declive de las instituciones y de la cultura urbanas, la constitución de nuevas ciudades fue promovida entre los siglos IV y vi tanto en Oriente como en Occidente. Se trata, sin embargo, de un aspecto de la Historia institucional romana al que se le ha dedicado muy escasa atención, al menos por cuanto se refiere al análisis sistemático de los casos documentados en las fuentes ${ }^{2}$. Uno de los promotores de fundaciones de ciudades más destacados de la Antigüedad fue Constantino. El ejemplo de Constantino que fue seguido por sus sucesores como su modelo político tanto en este como en otros aspectos (incluso por Juliano) ${ }^{3}$, dio así lugar a ciudades como Julianópolis, Basilinópolis, Zenópolis (en número de cuatro), Anastasiópolis (en número de nueve) y Justinianópolis (en número de quince) $)^{4}$. No obstante, la ausencia de un trabajo que examinara detalladamente la cuestión ha llevado a la construcción de una serie de espejismos historiográficos. El primero de ellos es la finalidad y la eficiencia de dicha política desde el punto de vista administrativo, pues el examen de los casos documentados, a pesar de la parquedad de las fuentes, permite advertir que su fin era esencialmente propagandístico, ya que, por lo general, no se realizaron fundaciones efectivas, sino simples modificaciones del estatuto jurídico de comunidades ya existentes. El segundo es su presunta vinculación a la política religiosa del emperador favorable al cristianismo. Según esta teoría, un cierto número de comunidades de ciudadanos constituidas como pagi y dependientes de otras ciudades, mayoritariamente paganas, obtuvieron del emperador la autonomía municipal alegando ser de mayoría cristiana ${ }^{5}$. A pesar de que algunos autores eclesiásticos dan cuenta de esta noticia, a efectos jurídicos, el Derecho romano no preveía la concesión de la autonomía municipal por razón de profesar el cristianismo, sino, en todo caso, en virtud del principio de autonomía reli-

2 A título de excepción, se pueden citar dos artículos: Lepelley, Cl., «La création de cités nouvelles en Afrique au Bas-Empire: le cas de la ciuitas Faustianensis", L'Afrique, la Gaule, la religion à l'époque romaine. Mélanges à la memoire de Marcel Le Glay rassemblés avec la collaboration d anciens élèves par Yann Le Bohec, Bruxelles, 1994, pp. 288-299; Arce Martínez, J., «La fundación de nuevas ciudades en el Imperio Romano tardío: de Diocleciano a Justiniano (siglos IV-VI)», Ripoll, G., y Gurt, J. M. (eds.), Sedes Regiae (ann. 400-800), Barcelona, 2000, pp. 31-62.

3 Marcone, A., «ll destino dell'Impero e la fortuna di Costantino», Chausson, F., y Wolff, É. (eds.), Consuetudinis amor. Fragments d' histoire romaine (Ile. Vle. siècles) offerts à Jean-Pierre Callu, Roma, 2003, pp. 311-321.

4 Jones, A. H. M., The Later Roman Empire (284-602). A Social, Economic and Administrative Survey, Oxford, 1964, p. 719; Arce Martínez, J., «La fundación de nuevas ciudades..., p. 43.

5 Barnes, T. D., Constantine and Eusebius, Cambridge, 1981, p. 38; Cameron, A., y Hall, S. G., Eusebius. Life of Constantine. Translated with Introduction and Commentary by, Oxford, 1999, pp. 22-31, 167, 327-328; Odahl, Ch. M., Constantine and the Christian Empire, London and New York, 2005, p. 250; Edwards, M., «The Begginnigs of Christianization», Lenski, N. (ed.), The Cambridge Companion to the Age of Constantine, New York, 2006, pp. 137-158, esp. p. 139.

6 Frateantonio, Chr., Religiöse Autonomie der Stadt im Imperium Romanum, Tübingen, 2003. 
giosa de las ciudades ${ }^{6}$, unido siempre a otros requisitos, entre ellos, tener un número suficiente de personas susceptibles de ser inscritas como curiales y disponer de recursos económicos suficientes para mantener las instituciones municipales ${ }^{7}$. Por otra parte, la fundación más recordada de Constantino es, sin duda, Constantinopla, si bien es cierto que se trata de la menos representativa, en tanto que pronto fue constituida como la Nueva Roma, la capital de la Pars Orientis del Imperio ${ }^{8}$. De hecho, con las excepciones de Arelate, Augustodonum, Cirta, y, desde luego, Constantinpla, las ciudades fundadas por Constantino corresponden normalmente a pequeños núcleos urbanos provinciales, sin significativa relevancia administrativa.

Todo ello conviene en reforzar la opinión de que la política constantiniana de fundación de ciudades no tuvo otro cometido que la propaganda política, concretamente, presentar a Constantino como un segundo Alejandro de Macedonia y segundo Augusto. Constantino evocó en distintos momentos de su carrera política los modelos de Alejandro y Augusto, en parte obligado por la necesidad de justificar sus continuas infracciones de las normas que legitimaban el acceso al poder imperial. Augusto representaba el princeps ciuilis ideal, elevado a la condición de príncipe por consenso de todos los ciudadanos (per consensum uniuersorum $)^{9}$. Entre tanto, Constantino, al comparar su persona y política con las de Alejandro, se presentaba como un soberano beneficiario de la elección divina para el imperio, lo cual se manifestaba en sus victorias militares sobre los enemigos externos e internos, a saber, bárbaros y tiranos. Pero Constantino también se equiparó a Alejandro al presentarse a través de la oratoria epidíctica como un varón que mantenía una particular relación con las divinidades, ilustrada en hechos como la visión de Apolo en Grand o la visión del caeleste signum Dei (cristianizada como la visión de la Cruz) la víspera de la batalla de Puente Milvio, ambas oportunas reelaboraciones de pasajes de la Historia Alexandri de Q. Curcio Rufo y de la biografía de Aureliano en la Historia Augusta ${ }^{10}$. La fundación

7 Arce Martínez, J., «La fundación de nuevas ciudades..., pp. 33-36, 44.

8 Sobre la fundación de Constantinopla y sus motivaciones políticas, cf. Mazzarino, S., «La data dell'Oratio ad Sanctorum Coetum, il ius Italicum e la fondazione di Costantinopoli: note sui discorsi di Costantino", Mazzarino, S., Antico, tardoantico ed èra costantiniana, I, Città di Castello, 1974, pp. 99-150; Dagron, G., Naissance d'une capitale. Constantinople et ses institutions de 330 a 451, París, 1984; La Rocca, E., «La fondazione di Costantinopoli», Bonamante, G., y Fusco, F. (eds.), Costantino il Grande dall' Antichità all' umanesimo. Colloquio sul Cristianesimo nel mondo antico. Macerata, 18-20 dicembre 1990, Macerata, 1993, pp. 553-583; Mango, C., Byzantium. The Empire of New Rome, Phoenix-London, 1994.

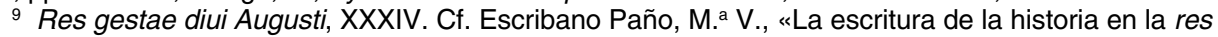
publica: las Res Gestae Diui Augusti», Marco Simón, F., Pina Polo, F., Remesal Rodríguez, J. (eds.), Repúblicas y ciudadanos: modelos de participación cívica en el mundo antiguo, Barcelona, 2006, pp. 167190 , esp. p. 185.

10 Q. Curcio Rufo, Historia Alexandri, IV, 2, 17; Historia Augusta. Aurelianus, 24, 2-8; Paneg. VI (VII), 21, 4-7; Paneg. XII (IX). Cf. Alföldi, M. ${ }^{a}$ R., " Signum Deae. Die kaiserzeitlichen Vorgänger des Reichsapfels", Jahrbuch für Numismatik und Goldsgeschichte, 11 (1961), pp. 19-32; MacMullen, R., Constantine, London, 1969, pp. 72-77; Dimaio, M., Zeuge, J., y Zotov, N., «Ambiguitas Constantiniana: the Caeleste Signum Dei of Constantine the Great», Byzantion, 58 (1988), pp. 333-360; Corsaro, F., "Sogni e visioni nella teologia della vittoria di Costantino e Licinio", Augustinianum, 29 (1989), pp. 333-349; Rodríguez Gervás, M. J., "Los sueños de Constantino en autores paganos y crisitianos», Propaganda política y opinión pública en los panegíricos latinos del Bajo Imperio, Salamanca, 1991, pp. 133-147; Gurruchaga, M., "Apéndice. La visión de la Cruz (Vit. Cons., I, 28)», Eusebio de Cesarea. Vida de 
de ciudades o la simple concesión de sobrenombres honoríficos derivados de su nombre o el de miembros de la familia imperial sólo se podían realizar en aquellos lugares donde se hubiera constatado una victoria militar. Fundar una ciudad o concederle un sobrenombre era una forma de reforzar y perpetuar la memoria de una victoria ${ }^{11}$. Por eso, al igual que Alejandro fundó a lo largo de los territorios que conquistó ciudades con el nombre de Alexandreia, Constantino hizo lo propio, primero, en las provincias bajo su autoridad, y, luego, en la totalidad del Imperio. Por ello, fundar ciudades equivalía a refundar y extender el propio Imperio Romano. Esta asociación entre victoria militar, ejercicio del poder imperial y fundación de ciudades fue muy pronto reflejada en las inscripciones honorarias dedicadas al emperador, en las que se apelaba a Constantino ni más ni menos que como conditor adque amplificator orbis Populi Romani sui ac singularum quarumque ciuitatum ${ }^{2}$.

Asociada a esta idea estaba el predicado de que la victoria del emperador no comportaba sumisión, sino el beneficio de la paz y la concordia civil, pues se traducía en la concesión de privilegios, quizá más honoríficos que reales, a las ciudades afectadas ${ }^{13}$. En efecto, las victorias de Constantino sobre sus sucesivos antagonistas políticos (Maximiano, Majencio y Licinio) fueron presentadas como una restitución del orden perdido durante la tetrarquía, de ahí que la epigrafía pública apelara insistentemente al emperador como restitutor orbis ${ }^{14}$. No obstante, hay una sutil diferencia entre la política de fundación de ciudades de Constantino antes y después de 324: antes de la derrota de Licinio, Constantino, se identifica ante todo con Augusto, si bien evocaba también a Alejandro, por sus rasgos carismáticos. Sin embargo, después de la conquista de las provincias orientales, Constantino acentúa los rasgos helenísticos de su discurso político, comparándose preferentemente a Alejandro. Y de ahí su interés en significar este hecho mediante la refundación de Bizancio como Constantinopla y la elevación de esta ciudad a la condición de Nueva Roma y segunda capital del Imperio.

Constantino. Introducción, traducción y notas, Madrid, 1994, pp. 399-411; Brandt, H., «Die «heidnische Vision» Aurelians (HA, A 24, 2-8) und die «christliche Vision» Konstantins des Grossen», Bonamente, G., y P., G. (eds.), Historiae Augustae Colloquium Maceratense, Bari, 1995, pp. 107-117; Weber, G., Kaiser, Träume und Visionen in Prinzipat und Spätantike, Stuttgart, 2000, pp. 278-282; Escribano Paño, M. ${ }^{a}$ V., «La primera visión de Constantino (310)», Teja Casuso, R. (coord..), Sueños, ensueños y visiones en la Antigüedad pagana y cristiana, 2002, pp. 85-94.

11 Dagron, G., Constantinople imaginaire. Études sur le recueil des patria, Paris, 1984, pp. 78-97.

12 CIL VIII, 1179 (=14309). Cf. Mastino, A., «Orbis, kósmos, oikuméne, aspetti spaziali dell'idea di impero universale da Augusto a Teodosio", Popoli e spazio romano tra diritto e profezia, Napoli, 1986, pp. 63-162, esp. pp. 109, 128, 132; Grünewald, Th., Constantinus Maximus Augustus. Herrschaftspropaganda in der zeitgenössischen Überlieferung, Stuttgart, 1990, p. 199 (N. $\left.{ }^{\circ} 119\right)$.

${ }_{13}$ CIL XIV 131 (= Dessau, 687) CIL VIII 7006 (= Dessau, 688); Eph. Ep., 7, 273 (Dessau, 690); CIL VIII, 7010 (= Dessau, 691).Cf. Farina, R., «La concezione della pace nel IV secolo. Costantino il Grande ed Eusebio di Cesarea», Dal Covolo, E., y Uglione, R., Chiesa e impero da Augusto a Giustiniano, Roma, 2001, pp. 185-195 (= Dal Covolo, E., y Uglione, R., Cristianizzazione e istituzioni politiche. Da Costantino a Giustiniano, Roma, 1997, pp. 95-105), esp. p. 188-189.

${ }_{14}$ Cil, V, 3331; CIL, VIII, 7006 (= DESSAU, 688); CIL, VIII, 7007; CIL XI, 6648; AE 1969-70, N. ${ }^{\circ} 107$; AE, 1974, 693. Cf. Mastino, A., «Orbis..., p. 143; Grünewald, Th., Constantinus Maximus Augustus..., pp. 195-196.. 
La evocación política de Alejandro estaba unida a la imitación de Augusto, que en su autobiografía política, las Res gestae diui Augusti, había asumido precisamente el título de conditor urbium ${ }^{15}$. En efecto, fundar ciudades, siquiera a título honorífico, equivalía a fomentar la participación de los ciudadanos en el gobierno del Imperio dentro de las curias municipales. De este modo, Constantino, al igual que Augusto o Trajano, se presentaba ante sus súbditos como un princeps ciuilis, pues en el ejercicio de su imperio no mermaba, sino que aumentaba, la posibilidad de que participaran en el gobierno, aunque fuera dentro de los municipios. Esto comportaba un respeto, siquiera teórico, formal, de la libertas de los ciudadanos, que, cuando menos, podían ejercerla en su ciudad. Por ello Constantino insistía tanto en el rescripto por el que concedía el estatuto de ciudad a Orcistus en manifestar su interés por fundar nuevas ciudades, mantener las antiguas y reparar las «medio muertas» (sic: intermortuas) ${ }^{16}$. La libertas de los ciudadanos ejercida en el marco institucional del municipio podía ser reforzada mediante la concesión de privilegios. De hecho, por contradictorio que parezca, la política administrativa de los siglos III y IV, que había tratado de equiparar el estatuto jurídico de las ciudades con vistas a una mayor eficiencia administrativa ${ }^{17}$, fomentó, al mismo tiempo, la política de concesión de privilegios a los municipios. Aparte de que la equiparación jurídica de todas las ciudades era una política irrealizable en un ente administrativo tan complejo y extenso como era el Imperio romano, la política de concesión de privilegios era absolutamente necesaria para garantizar la adhesión de los ciudadanos al emperador. La Historia Augusta atribuye a Adriano una carta dirigida al cónsul Serviano donde el emperador admite haber concedido a los alejandrinos todos los privilegios que le solicitaron, confirmando al mismo tiempo los que ya tenían, sólo para que le dieran las gracias ${ }^{18}$. La carta es evidentemente apócrifa y anacrónica, pero refleja cuál era la actitud política de los emperadores cuando les eran presentadas las preces de las ciudades relativas a la concesión de cualquier privilegio a finales del siglo Iv, que probablemente era la misma que habían adoptado los príncipes desde la institución del Imperio.

La estabilidad del Imperio, basada en la lealtad de los ciudadanos al emperador, quedaba garantizada mediante la concesión de privilegios. El emperador no estaba obligado a conceder privilegios, pero le era necesario hacerlo, para evitar ser considerado un tirano. Por esa razón debía demostrar liberalitas con relación a la capacidad de los ciudadanos de ejercer sus derechos políticos. Lo cual, como no podía ser de otro modo, también aparece reflejado en la epigrafia honoraria dedicada al emperador, pues Constantino es elogiado por su liberalitas y clementia hacia las ciudades en su aspecto institucional (es decir, los privilegios) y material (la

15 Res gestae diui Augusti, III, 3; XVI, 1. Cf. Arce Martínez, J., «La fundación de nuevas ciudades..., p. 37, n. 23.

16 Dessau, 6091.

17 Lepelley, Cl., «Vers la fin..., pp. 455-472.

18 Historia Augusta, Quadraginta Tyranni, VIII, 1-10. Cf. Baldini, A., «L'epistola pesudoadrianea neIla Vita di Saturnino», Bonamente, G., y Paci, G. (eds.), Historiae Augustae Colloquium Maceratense, Bari, 1995, pp. 35-56. 
munificencia pública) $)^{19}$. Al fin y al cabo, la mayor parte de los ciudadanos sólo podían ejercerlos en los municipios. Por ello, la política de fundación de ciudades o de concesión de privilegios a las mismas estaba unida a la carrera política de cualquier emperador y Constantino no fue una excepción. Constantino aprovechó los buenos resultados de sus campañas contra los francos de 306-307 para conceder sobrenombres honoríicos o modificar los estatutos de ciudades de la Diócesis Gallica, como Ciuitas Constantina (Cotantin), Constantia Castra (Coutances), Flauia Aeduorum (Augustodonum), Constantia (Constanza), Constantia (VIcisa Castra, actualmente Senzt-Endre), Castra Constantini (Batauodorum VIpia Nouiomagus, la actual Neumagen), y Constantia lulia (Lacimurga, en la provincia Bética). Después de la victoria sobre su suegro Maximiano en 310, Constantino concedió a Arelate el sobrenombre de Constantina. Una vez lograda la victoria sobre Majencio en 312, recibieron igual tratamiento varias ciudades situadas en Italia (Constantiniana - Luceria de Apulia-, Ciuitas Flauia Constantiniana Portuensis, junto a Ostia) África (Cirta Constantina) y en la Diócesis Panónica (Constantia, la antigua Margum, en Moesia Superior). Después de la derrota de Licinio en 324 y de la incorporación de las provincias orientales bajo su autoridad fue fundada Constantinopla como Nueva Roma, seguida de la concesión del estatuto de ciudad a Orcisto (Frigia), Maiuma Constantia, Antaradus Constantina y Helenópolis en Palestina, Constantia o Constantina de Arabia y de la concesión de sobrenombres honoríficos a Drépanon (Helenópolis de Frigia), Constantiniana Dafne, Salamina (Constantia de Chipre) y Antinópolis Tella (Constantia o Constantina, en Mesopotamia, actualmente Sheik Ibada). De la misma época es la concesión del sobrenombre de Flauia Constans a la ciudad umbra de Hispellum (Spello). No obstante, las razones de la fundación de cada ciudad fueron particulares, por lo que es necesario evitar suponer que el conjunto de estas medidas obedeciera a un planteamiento programático de la política de fundación de ciudades de Constantino. Para empezar, no todas ellas respondían a los mismos fines. Por número, desde luego, predominan las fundaciones o concesiones de títulos honoríficos, seguida de las concesiones de estatutos de ciudad a comunidades dependientes de otras (Orcistus, Maiuma y Antaradus), y, como la gran excepción, Constantinopla. En cualquier caso, Constantino no realizó ninguna fundación ex nouo, pues, como ya advirtió J. Arce, en la Antigüedad tardía, todas las concesiones de estatutos de ciudades se realizaron sobre núcleos preexistentes y con un número de personas suficientes para formar una curia ${ }^{20}$. De todos modos, cierto es que se sabe muy poco, además del nombre y una fecha aproximada, acerca de las fundaciones constantinianas, modelo de las llevadas a cabo por sus sucesores, ya que las noticias que hacen referencia a ellas son muy escasas, ya sean literarias, jurídicas, epigráficas o numismáticas. No obstante, los actuales avances de la investigación permiten disponer de una serie de referencias suficientes como para poder ofrecer una interpretación serena de la cuestión que se plantea.

19 Cil, VIII, 1179 (...) singularum ciuitatum adque ornatum liberalitate clementiae suae augenti (...). Cf. Mastino, A., «Orbis..., p. 109, n. 347. Sobre las virtudes que debían manifestar los emperadores en sus medidas de gobierno, cf. Wallace-Hadrill, A., «The Emperor and His Virtues», Historia, 30 (1981) 3, pp. $298-323$.

20 Arce Martínez, J., «La fundación de nuevas ciudades..., p. 44. 


\section{LA CONCESIÓN DE SOBRENOMBRES HONORÍFICOS A CIUDADES}

La concesión de un sobrenombre no comportaba la refundación de la ciudad, pero modificaba un elemento tan constitutivo de la misma como su nombre. De hecho, la acción jurídica de otorgar un nuevo nombre a una ciudad ya constituida, quedaba restringida, en principio, al propio hecho de nomen dare ${ }^{21}$. No comportaba, por tanto, la reiteración de fundación la ciudad, aunque sí constituía una rememoración de la misma. En principio, la concesión de un nuevo nombre no implicaba necesariamente la mejora del estatuto jurídico de una ciudad, aunque el simple hecho ya era considerado un privilegio a favor de sus ciudadanos, en tanto que eran beneficiarios de un privilegio imperial. En efecto, la concesión de un sobrenombre derivado del nombre del emperador o de alguno de sus familiares indicaba que la ciudad tenía una relación privilegiada con el príncipe benefactor. De alguna forma, implicaba la adopción de la ciudad por parte de un emperador como si fuera una fundación suya. En cualquier caso, a efectos jurídicos, la concesión de un sobrenombre a una ciudad no tenía ninguna repercusión a efectos de modificar su estatuto, ya que, en virtud de la Constitutio Antoniniana de $212^{22}$, que otorgaba a todos los habitantes del Imperio la condición de ciudadanos romanos de pleno derecho, todas las ciudades disfrutaban de la misma condición jurídica. De todas formas, aunque no existiera ninguna norma escrita al respecto, la concesión de sobrenombres honoríficos a ciudades por parte de los emperadores no podía ser arbitraria. Como todo privilegio, debía ser realizada a título excepcional y no general. De hecho, la concesión abusiva de sobrenombres honoríficos, como fue la de Constantino, no estaba bien contemplada por la ideología política del principado. Baste recordar que el emperador Adriano era celebrado en la Historia Augusta como ejemplo de príncipe que, si bien concedió a muchas ciudades sobrenombres honoríficos derivados del suyo, recurrió a esta práctica muy a su disgusto ${ }^{23}$.

Idealizaciones literarias aparte, la adopción de este tipo de medidas no obedecía tanto al gusto de los emperadores cuanto a su interés político. No es casual que Constantino adoptara este tipo de medidas desde sus primeros años de gobierno, en parte como una forma de salvar, desde el punto de vista de la propaganda política, la disgregación fáctica del poder producida con la institución del sistema tetrárquico. De alguna forma, la concesión de sobrenombres imperiales a las ciudades provinciales permitía salvar la distancia, geográfica e ideológica, entre los centros de poder, comenzando por Roma, y las ciudades situadas en la periferia provincial. No obstante, teniendo en cuenta el modesto lugar que ocupaba Constantino en el colegio tetrárquico, la concesión en fechas tan tempranas de sobrenombres a ciudades provinciales era una política bastante arriesgada, pues en

21 H. A., Vita Hadriani, XX, 4.

22 P. Giessen, I, n. ${ }^{\circ}$ 40. Existe una reciente lectura del papiro, acompañada de su correspondiente traducción alemana, que difiere en algunos puntos de la publicada por S. Riccobono (Fira, I, 58). Cf. Kuhlmann, P., Die Giessener literarischen Papyri und die Caracalla-Erlasse. Edition, Übersetzung und Kommentar, Giessen, 1994.

23 H. A., Vita Hadriani, XX, 4. 
principio, eran decisiones que sólo competían al primero de los Augustos. En 307, Constantino sólo era Augusto por concesión de Maximiano ${ }^{24}$. La conferencia de Carnuntum todavía le relegaría al título de César ${ }^{25}$. Es decir, todas estas medidas eran, cuando menos, ilegítimas ${ }^{26}$. No obstante, Constantino no dudó en realizar concesiones de sobrenombres, derivados del nombre de su padre Constancio o del nombre de su familia, la gens Flauia, pues hubiera sido demasiado osado que derivaran de su propio nombre.

Dada la parquedad de las fuentes, es imposible precisar el orden de las concesiones y sus motivos precisos, aunque todas ellas parecen corresponder a un contexto bélico, concretamente las campañas de Constantino contra los germanos entre 306 y 307 , y, sobre todo, el enfrentamiento por el poder entre los propios miembros del colegio imperial ${ }^{27}$. Si la concesión de un sobrenombre celebraba la victoria de un emperador sobre los enemigos externos, al tiempo que suponía un reconocimiento de la ayuda prestada por los provinciales en la campaña, era también una reafirmación de poder frente a los adversarios políticos ${ }^{28}$. Esto explica el riesgo asumido por Constantino al adoptar estas medidas. No obstante, por su propia seguridad, Constantino prefirió evocar la figura de su padre, Constancio Cloro, a cuyo prestigio como gobernante y general debía en buena parte su aclamación imperial en Eboracum. Ejemplo de ello son las concesiones de sobrenombres a distintas ciudades más o menos próximas al limes renano. Así, la antigua ciudad de Cosedia recibió el sobrenombre de Constantia Castra, cuyo centro urbano parece corresponder a la actual ciudad normanda de Coutances ${ }^{29}$. Por las mismas fechas, la antigua VIcisa Castra, la actual localidad de Senzt-Endre, recibió el sobrenombre de Constantia ${ }^{30}$. También recibieron entonces el sobrenombre de Constantia la antigua Margum $^{31}$ y la actual Constanza ${ }^{32}$. Probablemente estas

24 Stefan, A., «Les jeux d'alliances des tétrarques en 307-309 et l'élévation de Constantin au rang d'Auguste. À propos de CIL, III, 12121, IK 56, 19, AÉp. 2002, 1293», Antiquité Tardive, 14 (2006), pp. 187-216, esp. 202-204.

25 Bruun, P., «The Negotiations of the Conference of Carnuntum», Numismatica e Antichità Classiche, 8 (1979), pp. 255-278; Kuhoff, W., Diokletian und die Epoche der Tetrarchie. Das römische Reich zwischen Krisenbewältigung und Neuaufbau (284-313 n. Chr.), Frankfurt am Main, 2001, pp. 826-841; Stefan, A., «Les jeux d'alliances..., esp. 204-209.

${ }^{26}$ Leadbetter, B., «The Illegitimacy of Constantine and the Birth of the Tetrarchy», Lieu, S. N. C., y Montserrat, D. (eds.), Constantine. History, Historiography and Legend, London, 1998, pp. 74-85; Stefan, A., «Les jeux d'alliances..., pp. 209-211.

27 Chastagnol, A., «L'accentrarsi del sistema: la tetrarchia e Costantino», Schiavone, A. (dir.), Storia di Roma, 3, 1, Torino, 1993, pp. 193-222; Barnes, D., Constantine and Eusebius..., pp. 28-43; Kuhoff, W., Diokletian und die Epoche der Tetrarchie...., pp. 796-802.

28 Bruun, P., «Portrait of a Conspirator: Constantine's Break with the Tetrarchy», Arctos, 10 (1976), pp. 5-25.

29 Amiano Marcelino, XV, 11, 3; Notitia Galliarum, II, 8; Notitia dignitatum Occ., XXXVII, 9 (= 20); XLII, 34. Cf. IHM, «Constantia, 10»), RE, III, 2, col. 768; IHM, RE, IV, 1, col. 957; Bowman, A. (ed.), The Cambridge Ancient History. Vol. 12. The Crisis of the Empire. A. D. 193-337, Cambridge, pp. 259 y 734. Cf. Gregorio de Tours, Historia Francorum, V, 18. Cf. Oldoni, M., Gregorio di Tours. La storia dei Franchi. Volume I (libri l-V). A cura di, Vicenza, 1981, p. 590, n. 77.

30 Notitia dignitatum Occ., XXXIII, 13 (= 34). Cf. Patsch, «Constantia, 6)», RE, IV, 1, col. 957.

31 CIL, III, 8141. Cf. Patsch, «Constantia, 7)», en RE, IV, 1, col. 957.

32 Notitia Galliarum, II, 8; Notitia dignitatum Occ. XXXVII, 9 (=20). Cf. Marmor, J., Geschichtliche Topographie der Stadt Constanz, Constanz, 1860; IHM, «Constantia, 8)», en RE, IV, 1, col. 957. 
medidas coinciden con la concesión a la ciudad de Nouiomagus (Neumagen) del sobrenombre de Castra Constantin ${ }^{33}$. Además, la ciudad bética de Lacimurga recibió el sobrenombre de Constantia lulia ${ }^{34}$. Parece que en el mismo período, entre 306 y 307, Constantino concedió a Augustodonum el sobrenombre de Flauia Aeduorum $^{35}$, con el cual rendía homenaje a la gens Flauia, lo que comportaba vincular su persona no sólo a su padre Constancio Cloro, sino también a su abuelo Claudio el Gótico. Conviene recordar a este respecto que, puesto que los orígenes familiares de Constantino resultan un tanto oscuros, cuando menos humildes, por parte de madre, es en este momento, en los inicios de su carrera imperial, cuando tanto los panegíricos oficiales como la epigrafía exaltan la descendencia de Constantino, como nieto de Claudio e hijo de Constancio ${ }^{36}$.

La victoria sobre su suegro Maximiano en 310 reforzó el poder de Constanti$\mathrm{no}^{37}$. Este hecho se vio inmediatamente reflejado en las concesiones de sobrenombres a ciudades. La primera de ellas, Arelate, recibió el sobrenombre honorífico de Constantiniana ${ }^{38}$. Otro caso, probablemente coetáneo, aunque peor documentado, si cabe, es la concesión del sobrenombre de ciuitas Constantiniana a una ciudad conlimitánea de Constantia Castra, cuyo ager ha dado nombre a la actual comarca francesa de Cotantin ${ }^{39}$. Constantino siguió practicando esta política de concesión de sobrenombres después de su victoria sobre Majencio en 312, gracias a la cual obtuvo la autoridad sobre las provincias occidentales, en tanto que Licinio asumió la autoridad sobre las provincias orientales del Imperio. Después de haber vencido la resistencia de algunas ciudades del área véneta, como Verona, Constantino se hizo pronto con el mando de Italia, venciendo finalmente a Majen-

33 Ausonio, Mos., II. Cf. IHM, «Castra Constantini», RE, III, 2, col. 768.

34 Cil, II, 5550. Cf. Schulten, A., «Lacimurga», RE, XII, 1, col. 345.

${ }_{35}$ Paneg. Lat. VIII, I, ... Si Flauia Aeduorum tamen aeterno nomine nuncupata..., cf. Galletier, Pan. Lat., II, 1952, p. 89, n. 1.

${ }^{36}$ Dessau, 699; Dessau, 702. Cf. Pichon, J., Les derniers écrivains profanes, Paris, 1906, pp. 9398; Maurice, J., «La dynastie solaire des seconds Flaviens», Numismatique constantinienne, II, Paris, 1911, pp. XX-XLVIII; Maurice, J., «La dynastie solaire des seconds Flaviens», Revue Archéologique, 17 (1911), pp. 377-406; Baynes, N. H., The Historia Augusta: its Date and Purpose, Oxford, 1926, pp. 53 y sgs.; Syme, R., «The Ancestry of Constantine», Bonner Historiae Augustae Colloquium 1971, Bonn, 1974, pp. 237-245; Grünewald, Th., Constantinus Maximus Augustus..., pp. 25-41, 46-50; Lippold, A., «Kaiser Claudius II. (Gothicus), Vorfahr Konstantins d. Gr., und der römische Senat», Klio, 74 (1992), pp. 380-394; Baldini, A., «Claudio il Gotico e Costantino in Aurelio Vittore ed Epitome de Caesaribus», Bonamente, G., y Fusco, F., Costantino il Grande dall'Antichità all'Umanesimo. Colloquio sul Cristianesimo nel mondo antico. Macerata, 18-20 dicembre 1990, Macerata, 1993, II, pp. 73-89., pp. 81-84; Lippold, A., «Claudius, Constantius, Constantinus. Die V. Claudii der HA. Ein Beitrag zur Legitimierung der Herrschaft Konstantins aus stadrömischer Sicht», Bonamente, G., y Paschoud, F. (dirs.), Historiae Augustae Colloquium Perusinum (Atti dei Convegni sulla Historia Augusta, VIII), Bari, 2002, pp. 311-343, esp. 312-316, n. 35; Marcone, A., Pagano e cristiano. Vita e mito di Costantino, Roma, 2002, pp. 42-46.

37 E. Galletier, «La mort de Maximien d'après le panégyrique de 310 et la vision de Constantin au temple d'Apollon», en Revue des Études Anciennes, 52 (1950), pp. 288-299; W. HUSS, «Das Ende des Maximianus», en Latomus, 37 (1978), pp. 719-725.

38 León Magno, Ep. LXV: Memoriae Constantino peculiariter honorata est, ut ab eis uocabulo praeter proprium nomen, quo Arelas uocitatur, Constantina nomen accepit.

39 Gregorio de Tours, Historia Francorum, V, 18. En algunas ocasiones, se ha identificado erróneamente la Ciuitas Constantini con Constantia Castra. Cf. M. Oldoni, Gregorio di Tours. La storia dei Franchi. Volume I (libri I-V). A cura di, Vicenza, 1981, p. 590, n. 77. 
cio en Puente Milvio en $312^{40}$. Tan pronto como se difundió la noticia de la victoria de Constantino a las puertas de Roma, cierto número de ciudades manifestaron su adhesión al emperador en distintas partes de las provincias occidentales. Así, entre 312 y 313 , Luceria de Apulia recibió el nombre de Constantiniana ${ }^{41}$. Entre 312 y 313, Cirta recibió el sobrenombre honorífico de Constantina ${ }^{42}$. Entre 314 y 315 , Ciuitas Portuensis (junto a Ostia) recibió el nombre de Ciuitas Flauia Constantina Portuensis ${ }^{43}$. Estas concesiones comparten el hecho de celebrar la victoria de Constantino sobre Majencio, y, en general, fueron correspondidas por las ciudades beneficiaras con la dedicación de inscripciones conmemorativas. Quizá el caso más elocuente sea el de Cirta, que en dos inscripciones dedicadas a Constantino apela al emperador como Triumphator omnium gentium ad domitor uniuersarum factionum, qui libertatem tenebris seruitutis oppresam sua felici uictoria noua luce illuminauit. ${ }^{44}$ Por tanto, de acuerdo con la epigrafía municipal, las este tipo de concesiones obedecían estrictamente a la victoria de Constantino, primero, contra los enemigos externos (los bárbaros) y, segundo, contra los enemigos internos (el tirano Majencio). El resultado de esta victoria no fue sino la felicidad pública y la libertad de la servidumbre impuesta por los tiranos del pueblo romano, asociado todo ello a la lux noua, es decir, al resplandor del nuevo saeculum aureum que había inaugurado o se disponía a inaugurar Constantino con la celebración de los ludi saeculares de $314^{45}$.

40 Levi, M. A., «La campagna di Costantino nell'Italia settentrionale», Bollettino Storico-Bibliografico Subalpino, 36 (1934), pp. 1-10; Alföldi, A., "Cornuti. A Teutonic Contingent in the Service of Constantine and its Decisive Role in the Battle of the Milvian Bridge», Dumbarton Oaks Papers, 13 (1959), pp. 169-183; Scheithauer, A., y Weschklein, G., «Von Köln-Deutz nach Rom? Zur Truppengeschichte der Legio II Italica Divitensium», Zeitschrift für Papyrologie und Epigraphik, 81 (1990), pp. 229-236; Kuhoff, W., «Ein Mythos in der römischen Geschichte: Der Sieg Konstantins des Grossen über Maxentius vor den Toren Roms am 28. Oktober 312 n. Chr.», Chiron, 21 (1991), pp. 127-174.

41 CIL, IX, 801. Cf. Forni, «Flauia Constans Hispellum. Il tempio ed il pontefice delle gente Flavia Constantiniana", Atti dell'Accademia Romanistica Costantiniana. IX Convegno Internazionale, Perugia, 1993, pp. 401-406, esp. p. 403.

42 Aurelio Víctor, LX, 28: Cirtaeque oppido, quod obsidione Alexandri conciderat, reposito exornatoque nomen Constantina inditum. Cf. TABATA, K., «The Date and Setting of the Constantinian Inscription of Hispellum (CIL XI, 5265 = ILS 705)», Scripta Classica et Orientalia, 45 (1995), pp. 369-410, pp. 379 y 390-391.

43 CIL, XIV, 4449. Cf. Chevalier, R., Ostie antique, Paris, 1986, p. 127.

${ }_{44}$ CIL VIII, 7006 (= DESSAU, 688); CIL, VIII, 7007. Cf. Grünewald, Th., Constantinus Maximus Augustus..., pp. 202-203.

45 Turcan, R., Constantin et son temps. Le baptême ou la pourpre?, Dijon, 2006, p. 189. La celebración de los ludi saeculares en 314 tuvo un significado muy singular en la historia política, institucional y religiosa de Roma, pues, de acuerdo con Eunapio de Sardes y Zósimo, Constantino se negó a presidir los ritos sacrificiales tradicionales, sin atenerse a las prescripciones religiosas consuetudinarias. (Cf. Zósimo, Historia Noua, II, 7, 2). No obstante, los ludi saeculares fueron celebrados, con ludi pero sin sacrificios sangrientos, y Roma renovó su eternidad, claro está, de acuerdo con las formas festivas de la Antigüedad tardía. Cf. Fraschetti, A., «Costantino e il abbandono del Campidoglio», Giardina, A. (ed.), Società romana e impero tardoantico, II, Roma, 1986, pp. 412-438. Fraschetti, A., “Costantino e l'abbandono del Campidoglio", Seminario di Antichistica dell' Istituto Gramsci. Società romana e impero tardoantico. Roma. Politica, economia, paesaggio urbano, Roma, 1986, pp. 59-98; Fraschetti, A., La conversione. Da Roma pagana a Roma cristiana, Roma, 1999; Curran, J. R., Pagan City and Christian Capital. Rome in the Fourth Century, Oxford, 2000, pp. 74-75; Scheid, J., Quand faire, c'est croire. Les rites sacrificiels des Romains, Paris, 2005, pp. 97-110; 306-314. 
Otro tanto sucedió con la victoria de Constantino sobre Licinio en 324 . La derrota de Licinio supuso la desaparición del último vestigio de la institución tetrárquica. Constantino presentó este hecho como el fin de la división del Imperio, ya que después de la derrota de Licinio todas las provincias habían pasado a estar bajo una autoridad monárquica ${ }^{46}$. Teniendo en cuenta que la disgregación del poder imperial era considerada una de las causas que hacían al Imperio débil frente a las agresiones externas, Constantino no encontró mejor modo de celebrar el fin de las divisiones internas que la creación de una nueva capital para un nuevo Imperio reunificado, cuyo nombre derivaría del suyo: Constantinopla. La decisión de conferir a la ciudad de Bizancio el nombre de Constantino parece remontarse al mismo año de 324, en efecto de acuerdo con L. Cracco Ruggini, no resulta tan claro si la voluntad del emperador era refundarla a título de nueva capita ${ }^{47}$. Pero no fue hasta 328 cuando Constantinopla fue inaugurada como Nueva Roma de un nuevo Imperio. Por lo tanto, la institución de Constantinopla como nueva capital del Imperio es una medida adoptada como consecuencia de la victoria sobre Licinio, pero no fue inmediata. De hecho, la concesión del nombre de Constantinopolis a Bizancio en 324 es una medida más bien semejante a las concesiones de sobrenombres honoríficos a otras ciudades de las provincias orientales del Imperio. Así, en 327, Drépanon, lugar de nacimiento de Helena Augusta, la madre del emperador, fue refundada como Helenópolis de Frigia ${ }^{48}$. En 328, el castrum de Dafne, recibió el estatuto de ciudad con el nombre de Constantina Dafne ${ }^{49}$. De más incierta datación son la concesión del título de ciudad a Maiuma como Maiuma Constantia ${ }^{50}$, Antaradus como Antaradus Constantina ${ }^{51}$, una ciudad palestina de incierta identificación como Helenópolis ${ }^{52}$ y un castro hispano que recibió el nombre de Helena ${ }^{53}$. En fechas más inciertas, pero probablemente al mismo tiempo que las

46 Gaudemet, J., «Constantin, restaurateur de l'ordre», Studi in onore di S. Solazzi, Napoli, 1948, pp. 652-674; Farina, R., L'Impero e l'Imperatore cristiano in Eusebio di Cesarea. La prima teologia politica del cristianesimo, Zürich, 1966 p. 161, nn. 223-227; Dupont, Cl., «De quelques problèmes découlant de la conquête de l'Orient par Constantin. Leur solution par ce prince», Revue Internationale des Droits de l'Antiquité, 18 (1971), pp. 484-485; Farina, R., «La concezione della pace nel IV secolo. Costantino il Grande ed Eusebio di Cesarea», Dal Covolo, E., y Uglione, R. (eds.), Cristianesimo e istituzioni politiche da Costantino a Giustiniano, Roma, 1997), pp. 95-105 (= Dal Covolo, E., y Uglione, R. (eds.), Chiesa e Impero da Augusto a Giustiniano, Roma, 2001, pp. 185-195, esp. p. 193).

47 Cracco Ruggini, L., «Vettio Agorio Pretestato e la fondazione sacra di Costantinopoli», Philas chárin Miscellanea di Studi Classici in onore E. Manni, Roma, 1980, pp. 138 y sgs.; LA Rocca, E., «La fondazione di Costantinopoli», Bonamente, G., y Fusco, F., Costantino il Grande..., II, pp. 366 y ss.; Bonamente, G., «La «svolta costantiniana», Dal Covolo, E., y Uglione, R., Chiesa e impero..., pp. 145-170, esp. pp. 158-159. Sin embargo, S. Mazzarino defendió que Constantinopla fue concebida ya como segunda capital del Imperio en 324 e inagurada como tal ese mismo año, cf. Mazzarino, S., «La data dell'Oratio..., pp. 99-150.

48 Procopio, De aedificiis, V, 2; Barnes, T. D., Constantine and Eusebius..., p. 4; Tabata, K., «The Date and Setting..., pp. 379 y 381.

49 Amiano Marcelino, XXIII, 13, 1; Eckhel, J., Doctrina Nummorum Veterum, VIII, Wien, 1798, pp. 8182; Brenot, C., «Les monnaies au nom de Populus Romanus à Constantinople», Numismatica e Antichità Classiche, 9 (1980), pp. 302-304, n. 466; San Vicente, J. I., Moneda y propaganda política..., pp. 228-234.

50 Eusebio de Cesarea, V. C., IV, 38; Sozomeno, H. E., V, 3, 6-8.

51 Eusebio de Cesarea, V. C., IV, 39; Teófanes, Chron. LVII, 10; cf. Tabata, K., «The Date and Setting..., pp. 379-380.

52 Sozomeno, H. E., II, 2, 5. Cf. Tabata, K., «The Date and Setting..., pp. 379 y 381.

53 Eutropio, X, 9, 4. 
anteriores ciudades, fue concedido a Antinopolis Tella, en Mesopotamia (hoy Sheik Ibada), el sobrenombre de Constantia o Constantina ${ }^{54}$. También se sabe que una ciudad de Arabia recibió un sobrenombre que pudo ser Constantia o Constantina $^{55}$. Mejor conocida es la concesión, en 332, del sobrenombre de Constantia a Salamina, que pasó a ser conocida como Constantia de Chipre ${ }^{56}$. El último de estos casos que, se puede datar, con ciertas reservas, entre 333 y 335, parece ser la concesión a Hispello (la actual Spello, en Umbría) del sobrenombre de Flauia Constans, con ocasión de que dicha ciudad hubiera solicitado del emperador la institución de unos festivales sagrados anuales en honor del numen de la familia imperial ${ }^{57}$.

En relación con todos los casos anteriormente comentados, cabe señalar que no se trataron, en ningún caso, de fundaciones de ciudades, aunque la mera acción de otorgar un nuevo nombre a una ciudad ya existente suponía una rememoración de su fundación. En todo caso, conviene hacer una serie de observaciones al respecto. La primera, que Constantino recurrió constantemente a la imitatio Alexandri y la evocación de Augusto como modelo político en la adopción de estas medidas, comprendidas como un instrumento de propaganda política. Es necesario destacar que la concesión de sobrenombres a ciudades se concentra en los años inmediatamente posteriores a las distintas victorias de Constantino sobre sus adversarios, primero, contra los bárbaros, pero, sobre todo, contra los miembros del colegio tetrárquico, renuentes a reconocerle como partícipe del mismo (Constantia Castra, Flauia Aedorum, VIcisa Constantia, Margum Constantia, Constantia, Castra Constantini y Constantia Iulia), después contra Maximiano (Arelate Constantina, Ciuitas Constantina), más tarde contra Majencio (Cirta Constantina, Constantina de Apulia y Ciuitas Flauia Constantiniana Portuensis), y, por último, contra Licinio (Constan-

\footnotetext{
54 Teófanes, XXXVI, 16; Hierocles, Synecd., 714, 2. Cf. Fränkel, «Constantia, 4)», RE, IV, 1, col. 952.

${ }_{55}$ CIG, 4540; CIG, Add. P. 1180; Hierocles, Synecd., 723, 2; Notitia episc. Or., I, 1026. Benzinger, «Constantia, 2)», RE, IV, 1, col. 952.

${ }^{56}$ Jerónimo, Ep. CVIII:... Salamina Cypri, quae nunc Constantia dicitur... ; Sócrates, H. E., VI, 10; Teófanes, I, 29; I, 37. Cf. Patsch, «Constantia, 5)», RE, IV, 1, col. 952.

$57 \mathrm{CIL}$ XI, 5265. Cf. Adami, Storia di Volseno, A., II, 1734, pp. 48 y sgs.; Muratori, A. L., Raccolta di opusculi scientifici e filologici, Venezia, 1735, pp. 319 y sgs.; Muratori, A. L., Nouus thesaurus ueterum inscriptionum, III, Milano, 1740, pp. 1791-1794; Mommsen, Th., «Epigraphische Analekten, 9», Ber Sächs. Ges. d. Wiss., 8 (1850), pp. 199 y sgs. (= Gesammelte Schriften, VIII, 1913, pp. 24-45); Piganiol, A., «Notes Epigraphiques, I», Revue des Études Anciennes, 31 (1929), pp. 139-141; De Dominicis, M., «ll rescritto di Costantino agli Umbri e la Praetura Etruriae», Historia, IV (1930), pp. 470-480; Solari, A., «L'unione religiosa umbro-etrusca in un rescritto di Costantino", Studi Etruschi, 14 (1940), pp. 161-162; De Domincis, M., «ll rescritto di Costantino agli Umbri», Bullettino della Deputazione di Storia Patria per l'Umbria, LVIII (1961), pp. 5-22; De Dominicis, M., «Il rescritto di Costantino agli Umbri (nuove osservazioni)», Bullettino dell' Istituto di Diritto romano, 65 (1962), pp. 173-191; De Dominicis, M., "Un intervento legislativo costantiniano in materia religiosa (nota a CIL XI, 5265)", Revue Internationale des Droits de l'Antiquité, 10 (1963), pp. 189-211; Andreotti, R., "Contributo alla discusione del rescritto costantiniano di Hispellum», Atti del Primo Convegno di Studi Umbri, Perugia, 1964, pp. 249-290; Gascou, J., «Le rescrit d'Hispellum», Mélanges de l'Ecole Française de Rome, 79 (1967), pp. 609-659; Mancino, L., «Persistenza della religione etrusca in età tarda (rileggendo il rescritto costantiniano di Spello)", Atti del II Congresso Etrusco, II, 1990, pp. 1225-1235; Forni, G., «Flauia Constans Hispellum...., pp. 401-406; Tabata, K., «The Date and Setting...pp. 369-410; Goddard, Chr. J., «Les formes festives de l'allegeance au prince en Italie centrale sous le regne de Constantin: un suicide religieux? ", Mélanges de l'École Française de Rome, 114 (2002) 2, pp. 1025-1088.
} 
tinopolis, Helenópolis de Frigia, Constantia de Chipre, Helenópolis de Palestina, Constantiniana Dafne, Antinópolis Constantina y Constantia de Arabia). Casi todas ellas son fundaciones que evocan las sucesivas victorias militares de Constantino, primero en la Pars Occidentis y después en la Pars Orientis. La única excepción es Flauia Constans, sobrenombre otorgado a Hispellum en los últimos años del principado de Constantino. La razón parece clara: la concesión del sobrenombre no se trata de una espontánea disposición del emperador, sino de la respuesta, mediante rescripto, a la solicitud (preces) del municipio relativa a la institución de un templo, un sacerdocio y unos ludi en honor de la familia imperial.

La segunda observación es que estas medidas, aunque evidentemente respondían a un ejercicio de cálculo político, no fueron, como se puede pensar, programáticas. Es decir, no existió, propiamente dicha, una política constantiniana planificada de concesión de sobrenombres a ciudades, en el sentido de que hubiera previsto de antemano destinatarios, plazos y objetivos. Se trató, en efecto, de una política, entendida como práctica de gobierno, pero que fue aplicada según las circunstancias y conveniencias. El ejemplo más ilustrativo es Constantinopla. En su caso, cuando Constantino concedió a Bizancio el sobrenombre de Constantinopla, no preveía que más tarde dicha ciudad sería refundada como Nueva Roma, con un nuevo Senado Romano y un nuevo Capitolio. Pero también se puede recordar los casos de Constantia Castra y la vecina Ciuitas Constantina, en Normandía. Ambas ciudades, prácticamente conlimítrofes, recibieron el sobrenombre en fechas distintas y por circunstancias diversas, Constantia Castra entre 306 y 307, durante el período en el que Constantino estableció su corte en Tréveris, y Ciuitas Constantina quizá después de la derrota de Maximiano.

\section{LAS CONCESIONES DE ESTATUTOS DE CIUDAD}

Además de conceder sobrenombres honoríficos a ciudades que ya gozaban de tal condición, Constantino otorgó un cierto número de estatutos de ciudad a distritos municipales que, hasta ese momento habían dependido de otras ciudades. Es importante precisar que Constantino nunca fundó ciudades ex nouo, pues todas sus concesiones de estatutos de ciudad coinciden en corresponder a municipios que en un determinado momento habían perdido la condición de ciuitas. Por otra parte, estas concesiones no eran arbitrarias, pues los distritos o pagi que podían ser reconocidos legalmente como ciuitates debían de contar con unas determinadas características. La principal era que el distrito debía poder demostrar que tenía suficiente número de ciudadanos susceptibles de ser reclutados como curiales; la segunda, que el pagus contaba con suficientes propiedades públicas como para poder autofinanciarse el funcionamiento de las instituciones, y, por último, aunque no se trataba de requisito indispensable, pero sí vinculante, era que el distrito hubiera disfrutado previamente del estatuto de ciuitas.

Al menos, tres de los seis casos conocidos de concesiones de estatuto de ciudad debidos a Constantino contaron con esta condición: haber sido antes municipio autónomo. Estas ciudades son Cillium en Bizacena, la Ciuitas Tropaeensium en 
Tracia y Orcistus, en Frigia. Quizá podría incluirse en este grupo Constantia de Arabia, ciudad de la que apenas se tiene constancia documental, y, que puede que se tratase de una fundación constantiniana. Los otros tres restantes, Maiuma Constantia, Antaradus Constantina y Helenópolis de Palestina, sin embargo, han sido tradicionalmente interpretados como concesiones de estatutos de ciudad por razones religiosas, en particular, porque la mayor parte de los habitantes de dichos distritos se declaraban cristianos, pero dependían de ciudades mayoritariamente fieles a los cultos tradicionales que eran, todavía la religión oficial del Imperio. Según algunos autores, como F. Jacques y F. Kolb, tales distritos obtuvieron la autonomía municipal por fundamentalmente por razones religiosas ${ }^{58}$. Lo cierto es que, a partir del testimonio de Eusebio de Cesarea, algunos autores alegan las localidades palestinas de Maiuma y Antaradus obtuvieron de Constantino el estatuto de ciudad por la razón de declararse mayoritariamente cristianas ${ }^{59}$. Es probable que la concesión de la autonomía municipal a las dos ciudades palestinas se debiera a razones religiosas, pero este razonamiento no es aplicable ni a Cillium ni a la Ciuitas Tropaeensium ni a Orcistus. No obstante, cabe indicar que la jurisprudencia romana no contemplaba que una localidad pudiera obtener la autonomía municipal por razón de profesar el cristianismo. En todo caso, podía exigir la autonomía municipal alegando el principio de libertad religiosa de las ciudades. Claro está, que para recurrir a tal argumento debía demostrar que el distrito había sido constituido como ciuitas en algún momento. Pero, en cualquier caso, no era una razón suficiente, pues, en última instancia, los argumentos decisorios eran jurídicos (haber disfrutado previamente del estatuto de ciudad) y económicos (poder disponer de suficiente número de curiales y tener suficientes fuentes de recursos públicos). Lo demuestra la inscripción de Orcistus, que contiene el traslado epigráfico de tres documentos oficiales relativos a la concesión de autonomía de la ciudad. Estos documentos son: a) la carta de Ablabio a los ciudadanos de Orcistus, por la que comunica la resolución favorable del emperador, y que debía acompañar la copia del rescripto «de ciuitate danda», b) la copia el rescripto imperial dirigido por Constantino al Prefecto del Pretorio Ablabio por el que era concedida la condición de ciuitas a Orcisto, c) las preces dirigidas entre 324 y 326 por los habitantes de Orcisto para conseguir para su uicus el estatuto de ciuitas, d) la copia del segundo rescripto imperial, fechado el 30 de junio de $331^{60}$.

58 Jacques, F., «Les moulins d'Orcistus..., p. 436; Kolb, F., «Bemerkungen..., p. 339.

59 Eusebio de Cesarea, V. C., IV, 37-39.

60 CIL, III 352=7000 (Dessau 6091). La inscripción ha sido objeto de estudio desde mediados del siglo xVIII, cf. Pococke, R., Description of the East, II, 2, London, 1745, p. 85; Pococke, R., y Milles, I., Inscriptionum antiquarum Graecarum et Latinarum liber, London, 1752, p. 10, N. ${ }^{\circ}$ 6; W. Hamilton, Researches in Asia Minor, Pontus and Armenia, I, London, 1842, p. 447, n. 152; Le Bas y Waddington, Voyage archéologique en Grèce et en Asie mineure: inscriptions grecques et latines, III, N. ${ }^{\circ}$ 1715; Mommsen, Th. «Stadtrechtbriefe von Orkistos und Tymandos», Hermes, 22 (1887), pp. 309-322 (=Gesammelte Schriften, V, 1908, pp. 540-551); Sterrett, J. R. S., Bulletin of the University of Texas, 1889, pp. 11-12; Chastagnol, A., «Les realia d'une cité d'après l'inscription constantinienne d'Orcistus», Ktèma, 6 (1981), pp. 373-379; Chastagnol, A., «L'inscription constantinienne d'Orcistus», Mélanges de l'École Française de Rome, 93 (1981) 1, pp. 381-416; Jacques, F., «Les moulins d'Orcistus. Rhétorique et géographie au IVe. siècle», Institutions, société et vie politique dans l'empire romain au IVe. siècle ap. J. C., Roma, 1992, pp. 431-446; Kolb, F., «Bemerkungen zur urbanen Ausstatung von Städten im Westen und im Osten des Römischen Reiches anhand von Tacitus, Agricola 21, und der konstantinischen Inschrift von Orkistos», 
En efecto, Orcistus obtuvo del estatuto de ciudad por razones de índole institucional y económica. En las preces elevadas a Constantino entre 324 y 326 (todavía no había sido ejecutado Crispo, ni condenada su memoria), aun conservadas fragmentariamente, los solicitantes pretextan que Orcisto era en origen un oppidum antiguo, constituido desde su origen como ciuitas (Patria nostra Orcistos uetustissimum oppidum fuit et ex antiquissimis temporibus ab origine etiam ciuitatis dignitatem obtinuit). Según A. Chastagnol, Orcisto conservó su condición de ciuitas al menos hasta $237^{61}$. Algo después, por razones desconocidas, quizá políticas, debió de perder su condición de ciudad, pasando a quedar integrada como uicus en la ciudad de Nacoleya ${ }^{62}$. No obstante, a la razón jurídica fue acompañada de los argumentos económicos: una comunidad que reclamara ser constituida como ciuitas debía poder mantener las instituciones que exigía la administración de una ciudad. Por ello, Constantino indica en el rescripto que dirige a Ablabio, citando el tenor de las preces de los orcistanos, que la ciudad era sede de mansio viaria en buenas condiciones para el uso público (mansio tamen utilis adque accomoda), poseía agua en abundancia (aquam ibi abundantem fluentiam), baños públicos y privados (lauacra quoque publica priuataque), foro ornamentado con las estatuas de antiguos príncipes (forum istatuis ueterum principum ornatum), testimonio monumental de que Orcisto fue ciudad en otro tiempo, y molinos que aprovechaban los saltos de agua del lugar. Orcisto, por lo tanto, obtiene la autonomía gracias a que gozaba de suficientes recursos económicos como para garantizar el funcionamiento de sus instituciones, además de que contaba con el precedente de haber sido constituida como ciudad en el pasado.

Pues bien, contra la opinión de Eusebio, la autonomía de las ciudades palestina de Maiuma y Gaza se decidieron en virtud de los mismos argumentos jurídicos. Esto no significa que la razón principal por la que estos distritos solicitaron al emperador la autonomía municipal no fuera la existencia de un conflicto religioso entre sus vecinos y la mayoría de los habitantes de la ciudad de la que dependían. A propósito de esto, es necesario destacar que ni Maiuma ni Antaradus recibieron la autonomía municipal por espontánea decisión imperial, como pretende Eusebio, ${ }^{63}$ sino por medio de sendos rescriptos, tal y como ocurrió en el caso de Orcistus. Por lo tanto, el relato de Eusebio, según quien Constantino concedió la auto-

Klio, 75 (1993), pp. 321-341; Feissel, D., «L'adnotatio de Constantin sur le droit de cité d'Orcistus en Phrygie», Antiquité Tardive, 7 (1999), pp. 255-267. El texto canónico de la inscripción, según figura en el CIL III, fue recogida por S. Riccobono en el tomo primero de las Fontes luris Romani Anteiustiniani (Firenze, 1941) con el N. ${ }^{\circ} 95$ (pp. 461-464). Esta lectura fue revisada por W. M. Calder (MAMA, VII (1956), N. ${ }^{\circ} 305$, pp. 69-74). Calder fue el último autor que pudo examinar la inscripción mediante autopsia en los años 50 , pues hoy en día se desconoce su dónde se encuentra. Su lectura ha sido aceptada por Chastagnol («L'inscription constantinienne..., pp. 384-388) y F. Kolb («Bemerkungen..., pp. 326-328).

${ }^{61}$ Buckler opinaba que Orcisto había perdido el estatuto de ciudad antes de dicha fecha (Cf. Buckler, W. H., Journal of Hellenic Studies, 57 (1937), pp. 1-10; Ruge, W., RE, XVIII, cols. 1090-1097), si bien A. Chastagnol defiende que Orcisto fue ciudad hasta dicha fecha, perdiendo su condición entre 237 y comienzos del siglo Iv (Cf. Chastagnol, A., «L'inscription constantinienne..., pp. 398-411). Otra posibilidad es que Orcisto nunca hubiera gozado de la condición de ciuitas, de modo que en sus preces incurrieron en falsía, según propone Jacques.

${ }_{62}$ Chastagnol, A., «L'inscription constantinienne..., p. 402.

${ }^{63}$ Frateantonio, Chr., Religiöse Autonomie..., p. 223. 
nomía a los mencionados distritos al enterarse de que sus ciudadanos habían destruido los templos y abatido las estatuas de culto, no responde al procedimiento que habitualmente se seguía para obtener la autoría municipal: el procedimiento per rescriptum ${ }^{64}$. Probablemente los distritos expusieron en sus preces dirigidas al emperador que la razón de su solicitud era la existencia de un conflicto religioso, amparándose en el hecho de que la administración de los cultos públicos tradicionales en cada ciudad era una competencia del municipio ${ }^{65}$. Cierto que el cristianismo y los cultos públicos tradicionales eran cosas distintas, pero, en virtud de los acuerdos de Milán de 312, el cristianismo había sido reconocido como religio ${ }^{66}$, y, a falta de otras normas, disfrutaba de condiciones jurídicas análogas a los cultos públicos tradicionales. No obstante, el segundo de los rescriptos de Orcistus (probablemente de 331) documenta que, en virtud del principio de libertad religiosa de las ciudades, aquellos municipios cuyos habitantes se declaraban cristianos en su totalidad o en su mayoría, podían obtener, cuando menos, la exención de algunas cargas fiscales relativas al sufragio de los cultos públicos. La vecina ciudad de Nacoleya reclamaba a Orcistus la pecunia pro cultis, pero, alegando ser que todos sus habitantes eran cristianos (así se entiende la expresión omnes ibidem sectatores sanctissimae religionis habitare dicantur) ${ }^{67}$, solicitaron y obtuvieron la exención del referido impuesto. Es decir, los ciudadanos de Orcistus reconocen implícitamente que la reclamación de Nacoleya era legítima, y, de hecho, había sido satisfecha con anterioridad. Ahora bien, desde el mismo momento en el que los orcistanos se habían declarado cristianos dicha exigencia resultaba ilegítima. De hecho, el rescripto imperial calificó la reclamación de la pecunia pro cultis de iniuria, es decir, un daño moral causado deliberadamente por los ciudadanos de Nacoleya contra los ciudadanos de Orcistus ${ }^{68}$, pues el mero hecho de contribuir a los cul-

64 Sobre el procedimiento per rescriptum, cf. De Robertis, F. M., «Sull'efficacia normativa delle costituzioni imperiali, 2. I rescripta principum», Annali della Facoltà di Giurisprudenza dell'Università degli Studi di Bari, 4 (1942), pp. 282 y sgs.; Vinci, «Sull'efficacia dei rescripta principum nel diritto romano», Annali della Facoltà di Giurisprudenza dell'Unversità degli Studi di Catania, 1 (1946-1947), pp. 320 y sgs.; Maggio, L., «Note critiche sui rescritti posclassici. 1. II c. d. processo per rescriptum», Studia et Documenta Historiae et luris, 61 (1995), pp. 285-312; Maggio, L., «Note critiche sui rescritti postclassici. 2. L'efficacia normativa dei rescritti ad consultationes e dei rescritti ad preces emissa», en Crifò, G., y Giglio, S. (ed.), Atti dell'Accademia Romanistica Costantiniana. XIV Convegno Internazionale in memoria di Guglielmo Nocera, Napoli, 2003, pp. 359-380.

${ }^{65}$ Frateantonio, Chr., Religiöse Autonomie..., pp. 34-27.

66 Lactancio, De mortibus persecutorum, XLVIII, 2. Cf. Sordi, M., «Pax deorum e libertà religiosa nella storia di Roma», AA. VV. La pace nel mondo antico, Milano, 1985, pp. 133 y sgs.

67 CIL III, 70, col. I, II. 23-42.

68 La legislación constantiniana, hasta ese momento, restringía el calificativo de iniuria en materia religiosa a las exigencias por parte de algunos municipios de que los clérigos celebraran sacrificios (CTh. $\mathrm{XVI}, 2$, 3, del año 323). Sobre el concepto de iniuria en la jurisprudencia romana y en la legislación constantiniana, cf. Dupont, Cl., «Injuria et délits privés dans les constitutions de Constantin», Revue Internationale des Droits de l'Antiquité, 1 (1952), pp. 423-444, esp. 426-428; Kunkel, W., «Exegetische Studien zur aquilischen Haftung», Zeitschrift der Savigny-Stiftung für Rechtsgeschichte (Romanistische Abteilung), XLIX (1929), pp. 158-187, esp. p. 168; Martini, R., Le definizioni dei giuristi romani, Milano, 1966, pp. 332335; Cannata, C. A., Per lo studio della responsabilità per colpa nel diritto romano classico, Milano, 1969, p. 307; Cannata, C. A., "Sul testo della Lex Aquilia e la sua portata originaria», Vacca (ed.), L., La responsabilità civile da atto illecito nella prospettiva storico-comparativa, Torino, 1995, p. 37; La Rosa, F., «ll valore originario di iniuria nella Lex Aquilia», Labeo, XLIV (1998), pp. 366-376, esp. p. 369; Cursi, M. ${ }^{a}$ F., 
tos tradicionales era incompatible con la observancia del cristianismo. Por lo tanto, es muy probable que las dos ciudades palestinas invocaran como una de las razones para solicitar la autonomía municipal el principio de libertad religiosa, declarándose cristianos sus ciudadanos, pero, al margen de ello, las ciudades tenían que demostrar su solvencia económica para poder obtener la autonomía municipal. En efecto, Maiuma era el puerto de Gaza, y las instalaciones portuarias garantizaban que la ciudad, lograda su autonomía, contaba con suficientes recursos públicos $^{69}$. Así mismo, Antaradus, al estar situada en un cruce de caminos, era un importante centro comercial de la región ${ }^{70}$.

No obstante, no siempre el argumento económico fue el decisivo en las concesiones de autonomía municipal por parte de Constantino. De hecho, Constantino asoció siempre la concesión de autonomía a distritos municipales a la restitutio libertatis lograda con sus sucesivas victorias sobre los tiranos. En efecto, Orcistus, Maiuma y Antaradus obtuvieron la autonomía municipal después de la derrota de Licinio. De este modo, Constantino hacía alarde de liberalitas, concediendo autonomía política a nivel municipal a distintos grupos de ciudadanos, contraponiéndose así a la renuencia de los tiranos a realizar este tipo de concesiones, llevados por una inclemente cupido dominandi. La restitutio libertatis como argumento de la concesión de autonomía municipal aparece en una inscripción de la ciudad de $\mathrm{Ci}$ Ilium, en Bizacena. Cillium obtuvo la autonomía municipal entre 314 y 316 , argumentando haber disfrutado previamente del estatuto de ciudad. En este caso, la concesión se produjo en el contexto político de la derrota de Majencio y del inicio de los enfrentamientos entre Constantino y Licinio ${ }^{71}$. La concesión de la autonomía municipal podía ser, por lo tanto, una medida de gracia derivada de una victoria imperial sobre los «tiranos». Así lo viene a indicar la inscripción de Cillium: Clementia temporis et uirtute / diuina dominorum nostrorum Constantini «et Licinii» inuictorum / semper Augustorum ornamenta libertatis restituta et uetera ciuitatis insignia curante Ceionio Aproniano clarissimo uiro / patrono ciuitatis. ${ }^{72}$

«Damnum e iniuria nella Collatio», Lucrezi, F., y Mancini, G. (eds.), Crimina e delicta nel Tardo Antico. Atti del Seminario di Studi. Teramo, 19-20 gennaio 2001 (Università degli Studi di Teramo. Collana della Facoltà di Giurisprudenza. Nuova Serie, 16), Milano, 2003, pp. 62-63, nn. 83-84.

${ }_{69}$ Eusebio, V. C., IV, 37; Sozomeno, HE, V, 3; VII, 28. Cf. Hölscher, «Maiuma, 1)», RE, XIV, 1, col. 610.

70 Benzinger, «Antarados», en RE, I, 2, col. 2347.

71 La historiografía moderna todavía no ha podido precisar con unanimidad la fecha de inicio de la guerra civil entre Constantino y Licinio. Parece claro que el desacuerdo político entre ambos comenzó en 314, pero la guerra civil no estalló hasta 316, con el Bellum Cibalense, datado en dicho año por Pohlsander. Sobre la cuestión, cf. Neri, V., «Un miliario liciniano ad Aquileia: ipotesi sui rapporti tra Costantino e Licinio prima del conflicto del 314", Rivista Storica dell'Antichità, 5 (1975), pp. 79-109; Alföldi, M. ${ }^{a}$ R., «Die Niederemmeler "Kaiserfibel», zum Datum des ersten Krieges zwischen Konstantin und Licinius", Bonner Jahrbucher, 176 (1976), pp. 183-200 (= Alföldi, M. ${ }^{a}$ R., Gloria Romanorum. Schriften zur Spätantike, Stuttgart, 2001, pp. 64-79); Di Maio, M., Zeuge, J., y Bethune, J., «Proelium Cibalense et Proelium Campi Ardiensis: The First Civil War of Constantine I and Licinius I", The Ancient World, 21 (1990), pp. 67-91; Ehrhardt, Chr., "Monumental Evidence for the Date of Constantine's First War against Licinius», The Ancient World, 23 (1992), pp. 87-94; Chastagnol, A., "Quelques mises au point autour de l'empereur Licinius", Bonamente, G., y Fusco, F., Costantino il Grande..., I, pp. 311-323, esp. pp. 314317; Pohlsander, H. A., «The Date of the Bellum Cibalense: A Reexamination», The Ancient World, 26 (1995) 1, pp. 89-101.

${ }_{72}$ CIL, VIII, 210 (Dessau, 5570). Cf. Grünewald, Th., Constantinus Maximus Augustus..., p. 203 (N. 138). 
Pero en otro caso, el de la Ciuitas Tropaeensium, en Tracia, contemporáneo a Cillium, la concesión del estatuto de ciudad a la localidad es presentada como una consecuencia de la victoria imperial sobre los bárbaros. La Ciuitas Tropaeensium es probablemente el único caso de fundación constantiniana ex nouo. La victoria imperial sobre los bárbaros conllevaba la ampliación de las fronteras y el refuerzo de la seguridad del Imperio. El nombre impuesto a la ciudad, Ciuitas Tropaeensium, indica que la fundación de la ciudad conmemora una victoria militar, celebrada con la acostumbrada erección del trofeo aprovechando los despojos del enemigo. Según la inscripción que documenta la construcción de la ciudad ex fundamentis, previa observancia de los auspicios prescritos por la consuetudo romana, la Ciuitas Tropaeensium responde al propósito explícito de asegurar el control de las fronteras (ad confirmandam limitis tutelam): Romanae securitatis libertatisque uindicibus / dominis nostris Flauio Valerio Constantino e Valerio Liciniano Licinio piis felicibus aeternis Augustis / quorum uirtute et prouidentia edomitis ubique barbarorum gentium populis / ad confirmandam limitis tutelam etiam / Tropaeensium ciuitas auspicato a fundamentis / feliciter opere constructa est / Petronius Annianus uir clarissimus et lulius lulianus uir eminentissimus praefecti praetorio numini eorum semper dicatissimi ${ }^{3}$. El caso de la Ciuitas Tropaeensium, que corresponde al de una ciudad de frontera fundada con fines defensivos, puede ser relacionado con medidas adoptadas por el propio Constantino como la concesión del sobrenombre de Constantina a VIcisa Castra y la concesión del sobrenombre de Castra Constantini a Nouiomagus en el limes renano, en el período de 306-307. No obstante, según demuestra la epigrafía, la celebración de las victorias militares sobre los bárbaros estaba unida a la celebración de la victoria sobre los tiranos ${ }^{74}$. Ello obedece a que el emperador era, por su propia naturaleza, un imperator semper inuictus, no un vencedor sobre partes, pues su condición de princeps a diis electus se reflejaba precisamente en sus victorias. No en vano, desde la perspectiva del ideario político romano, un emperador, siguiendo el ejemplo de Augusto, tenía que garantizar la estabilidad política de la res publica y la defensa del Imperio de sus enemigos externos.

Recuérdese a propósito de ello que prácticamente contemporánea a la fundación de la Ciuitas Tropaeensium es la concesión del sobrenombre de Constantia a Margum (Moesia Superior), en el limes danubiano. Esta misma política fue practicada en el limes oriental después de la victoria sobre Licinio, como demuestra la concesión del sobrenombre de Constantia o Constantina a Antinópolis en Mesopotamia y la probable fundación de Constantia o Constantinia de Arabia. Estas últimas concesiones o fundaciones ilustran claramente el recurso a la imitatio Alexandri por parte de Constantino, que jalonó de ciudades con su nombre los confines más extremos, a Occidente y Oriente, de su Imperio. Esta política no resulta tan clara antes de la derrota de Licinio, pues, por ejemplo, la Ciuitas

73 CIL, 13734 (= AE, 1894, 111). Cf. Grünewald, Th., Constantinus Maximus Augustus..., p. 242 (N. $\left.{ }^{\circ} 402\right)$.

74 Cil, III, 8502. Cf. Grünewald, Th., «Ein epigraphisches Zeugnis zur Germanenpolitik Konstantins des Groðen: Die Bauinschrift des Deutzer Kastells (CIL III, 8502)», Herzog, E., y Frei-Stolba, R. (eds.), Labor omnibus unus. Festschrift Georg Walser, Stuttgart, 1989, pp. 171-185. 
Tropaeensium no recibió un nombre derivado del de Constantino o de miembros de su familia. Ello responde a que la política de conceder sobrenombres a ciudades ya existentes o fundar ciudades en los limites del Imperio antes y después de 324 respondía a una concepción del espacio del Imperio romano bastante distinta: las concesiones de sobrenombres o fundaciones de Constantino anteriores a 324 responden más bien a un concepto esencialmente romano del Imperio, evocando el ideal de Imperio romano constituido por el principado de Augusto, en tanto que, después de 324, con la conquista de las provincias orientales, Constantino prefirió evocar el ideal de Imperio universal representado por la basileía helenística de Alejandro ${ }^{75}$. En este contexto debe ubicarse la audaz decisión constantiniana de fundar una segunda capital para el Imperio sobre la ciudad de Bizancio.

\section{LA FUNDACIÓN DE CONSTANTINOPLA}

Por lo general se ha soslayado la singularidad de la fundación de Constantinopla, pues no se ha considerado que la sola pretensión de fundar una «Nueva Roma», confiriéndole además su propio nombre, era un hecho con resabios tiránicos. Baste recordar que el único precedente era el rumor recogido por Tácito de que Nerón había ordenado incendiar Roma para fundar una Vrbs Noua que llevara su nombre ${ }^{76}$. No obstante, Constantino se cuidó mucho de que sus gestos políticos le hicieran comparable a Nerón. De hecho, su política de fundación de ciudades con nombres derivados del suyo o el de los miembros de la familia imperial no era sino una medida propagandística que trataba de equiparar a Constantino con Alejandro de Macedonia ${ }^{77}$. No obstante, como se ha indicado poco antes, la decisión de constituir Constantinopla como Nueva Roma no es inmediata a la conquista de las provincias orientales. En 324, en el contexto político inmediato a la derrota de Licinio, Constantino concedió a Bizancio el sobrenombre de Constantinopolis. La decisión de hacer de ella una Nueva Roma, de acuerdo con L. Cracco Ruggini, debe ser fijada en 328 , cuando la ciudad fue delimitada y augu-

75 Heisenberg, A., «Staat und Gesellschaft des Byzantinischen Reiches», Die Kultur den Gegenwart, II, IV, 1, Leipzig, p. 362; Zakythinos, D. A., «Continuité de l'Empire romain à Constantinople: 330-1453», Catalano, P., y Siniscalco, P., La nozione di «Romano» tra cittadinanza e universalità, Napoli, 1984, pp. 231-245.

76 Tácito, Ann., XV, 40: Plusque infamiae id incendium habuit quia praediis Tigellini Aemilianis proruperat uidebaturque Nero colendae Vrbis nouae et cognomento suo appellandae gloriam quaerere; Sulpicio Severo, Chron., III, 29: Sed opinio omnium inuidiam incendii in principem retorquebat, credebatur que imperator gloriam innouandae Vrbis quaesisse.

77 Sobre la imitatio Alexandri por parte de Constantino, cf. Burckhardt, J., Die Zeit Konstantins des Grossen, 1853, p. 109 (Cito trad. inglesa); Firth, J. B., Constantine the Great: The Reorganisation of the Empire and the Triumph of the Church, New York, 1905; Cochrane, Ch. N., Christianity and Classical Culture. A Study of Thought and Action from Augustus to Augustine, Oxford, 1941; Baker, A. E., From Alexander to Constantine: Passages and Documents Illustrating the History of Social and Political Ideas, Oxford, 1956, pp. 39 y sgs.; Barr, S., Mask of Jove. A History of the Graeco-Roman Civilization from the Death of Alexander to the Death of Constantine, Philadelphia-New York, 1966, p. 515; Ferguson, E., Backgrounds of Early Christianity, Oxford, 2003, p. 281. 
rada conforme a las consuetudines romanas ${ }^{78}$. Evidencia no determinante de que la ciudad todavía no había sido constituida como capital del Imperio fue que el Concilio convocado por Constantino en 325 para resolver la cuestión arriana fue celebrado en la vecina Nicea y no en Constantinopla, acaso un lugar más apropiado. Dos años más tarde, en 330, la ciudad fue dedicada a Fortuna Florentia, divinidad tutelar de la ciudad y garante de su perpetua seguridad y prosperidad $^{79}$. De alguna forma, la fundación de Constantinopla significó el abandono por parte de Constantino de la ideología política augustea y la adopción, en su lugar, del lenguaje político helenístico. Al igual que Alejandro fundó Alejandría a título de victoria sobre el Reino de Egipto, lo que representaba la transformación de la monarquía macedonia en una monarquía «universal», Constantino presentó la fundación de Constantinopla como la conclusión de su carrera política, en tanto que había logrado la reunificación de las dos partes Imperii bajo su autoridad. Pero además, Constantinopla fue presentada no sólo como nueva capital del Imperio romano, sino como capital de un Imperio universal. Ecos de estas ideas se pueden encontrar en la Vita Constantini de Eusebio de Cesarea, en los pasajes en los que se relata la recepción en Constantinopla de embajadas de distintos pueblos bárbaros (blemios, indios y etíopes), que acudían ante Constantino «para someterse a su autoridad», .80 Obviamente, no era ésta la finalidad de las embajadas extranjeras, pero lo cierto es que Constantinopla subrayó, a diferencia de Roma, su función de puerta del Imperio, debida, en buena parte, a su excepcional buena ubicación, pues, no en vano, el Bósforo une Asia y Europa. De hecho, la idónea localización de Bizancio parece que fue decisiva para que Constantino estableciera allí la Nueva Roma, por razones de pura estrategia de política territorial ${ }^{81}$.

Las razones de la fundación de Constantinopla distan mucho de ser claras. Por lo pronto, conviene descartar la posibilidad de que obedeciera a fines utilitarios. La única explicación aceptable es que se tratara de un gesto de carácter propagandístico: Constantino, como restaurador y renovador de la unidad del Imperio y fundador de un nuevo saeculum aureum, fundó una nueva capital para el Imperio, a la

78 Cracco Ruggini, L., «Vettio Agorio Pretestato..., pp. 138 y sgs. Cracco Ruggini revisa la datación más aceptada hasta el momento, que era la propuesta por Mazzarino, quien fijaba la delimitatio e inauguratio de Constantinopla en 324, la consecratio en 328 y la dedicatio en 330. Cf. Mazzarino, S., «La oratio...», pp. 123-12, n. 56. La inauguración de Constantinopla no aparece descrita en fuentes contemporáneas cristianas, probablemente porque la observancia de los ritos inagurales exigidos por el Derecho para las fundaciones de ciudades resultaba algo embarazoso toda vez que los autores eclesiásticos reconocían a Constantino como cristiano. En efecto, los relatos de la fundación de Constantinpla (Filostorgio, H. E., II, 9; Juan Malalas, Chronog., 324; Juan Lido, De magistratibus, IV, 2) son más bien tardíos (Ss. V y VI) lo que dificulta el conocimiento de los hechos. Cf. Dagron, G., Naissance d une capitale..., pp. 29 y 39; Dagron, G., Constantinopla immaginaire..., pp. 78-97; Varvounis, M. G., «Une tradition populaire sur la fondation de Constantinople», Byzantion, 66 (1996), pp. 454-460; Marasco, G., Filostorgio. Cultura, fede e politica in uno storico ecclesiastico del V secolo, Roma, 2005, pp. 133-135.

79 Paschalion, A. D. 328; Juan Malalas, Cronografía, 320. Cf. Dagron, G., La naissance d'une capitale..., p. 40; Pentcheva, B. V., Icons and Power. The Mother of God in Byzantium, Pennsylvania, 2006, pp. 16-21..

80 Eusebio de Cesarea, V. C., IV, 6-7.

81 Isidoro de Sevilla, Etymologiae, XV, 1, 42. Cf. Orselli, A. M. ${ }^{a}$, «Antica e nuova Roma nella storiografia del primo medioevo latino: Isidoro e Beda», Catalano, P., y Siniscalco, P. (eds.), Popoli e spazio romano tra diritto e profezia, Napoli, 1986, pp. 231-245. 
que dio su nombre ${ }^{82}$. Los autores cristianos hicieron coincidir la fundación de Constantinopla con la constitución del Imperio romano cristiano, haciendo ver que a un Imperio renovado en el carisma cristiano le correspondía una capital libre de templos y ceremonias idolátricas ${ }^{83}$. La idea sería aceptable si no fuera evidente que Constantinopla estaba plagada de despojos de templos de todo el Imperio y que en la acrópolis de Bizancio se alzaban los templos de Helios, Ártemis-Selene y Afrodita ${ }^{84}$. En otras palabras, Constantinopla no nació como una ciudad cristiana, sino absolutamente pagana, mediando, de hecho, los consuetudinarios ritos augurales, bajo la tutela de los dioses y del genio del emperador ${ }^{85}$. Además, el propio Constantino había desarrollado la idea de que Jerusalén era el centro geográfico-escatológico de la creación gracias a su política de construcción de basílicas cristianas en Palestina, para promover allí las primeras peregrinaciones a Tierra Santa ${ }^{86}$. Ciertamente, la decisión carecía de justificación administrativa, pues esa función la había desempeñado muy bien la antigua Roma. Tréveris, Mediolanum, Sirmium, Antioquía, Nicomedia, Tesalónica o Heraclea, que habían sido sedes imperiales tetrárquicas, estaban ya preparadas para esa función, pues había albergado oficinas administrativas imperiales y contaban con suficientes infraestructuras urbanas ${ }^{87}$. El propio traslado de las instituciones, así como la adecuación urbanística (incluída la costosa ornamentación de los espacios públicos) era un dispendio de fondos que el Estado apenas se podía permitir y que llevó, como observó Jerónimo, a la confiscación de bienes artísticos en muchas ciudades de la Pars Orientis. ${ }^{88}$ De hecho, la constitución de Constantinopla como nueva capital fue muy mal asumida por los ciudadanos de las provincias orientales, como bien se puede apreciar en la obra de Libanio ${ }^{89}$.

${ }^{82}$ Ullmann, W., «The Constitucional Significance of Constantine the Great's Settlement», Journal of Ecclesiastical History, 27 (1976) 1, pp. 1-16.

${ }_{83}$ Eusebio de Cesarea, V. C., III, 48. Paulo Orosio, Historia aduersos paganos, VII, 28, 27: Vrbem nominis sui Romanorum regum uel primus uel sollus instituit. Quae sola expers idolorum ad hoc breuissimo tempore condita a Christiano imperatore prouecta est, ut sola Romae, tot saeculis miseriisque prouectae, forma et potentia merito possit aequari.; Agustín de Hipona, De Ciu. Dei, V, 25: (...) cui etiam condere ciuitatem Romano imperio sociam, uelut ipsius Romae filiam, sed sine aliquo daemonum templo simulacroque concessit. (...).

84 Juan Malalas, Chronog., 324. Cf. Mango, C., Le développement..., pp. 23-36.

85 Alföldi, A., The Conversion of Constantine and Pagan Rome, Oxford, 1948, pp. 110-123; Maccormack, S., «Roma, Constantinopolis, the Emperor and his Genius», The Classical Quarterly, XXV (1975), pp. 131-150; Ando, Cl., «The Palladium and the Pentateuch: Towards a Sacred Topography of the Later Roman Empire», Phoenix, 55 (2001), pp. 369-410.

${ }^{86}$ Cirilo de Jerusalén, Catechesis, XIII, 28. Cf. Piganiol, A., «L'hémisphairion de l'omphalos des Lieux Saints", Cahiers Archéologiques, 1 (1945), pp. 7-14; Rahner, H., Griechischen Mythen in Christcher Deutung (1945), München, 1945 (Cito trad. castellana, Mitos griegos en interpretación cristiana, Barcelona, 2003, p. 79); Armstrong, G. T., "Constantine's Churches: Symbol and Structure», Journal of the Society of Architechtrual Historians, 33 (1974), pp. 5-16 (= P. C. Finney (ed.), Art, Archeology and Architechture of Early Christianity, London, 1993, pp. 1-11); Drijvers, J. W., Helena Augusta. The Mother of Constantine and the Legend of Her Finding of the True Cross, Leiden, 1992, p. 183; Wharton, A. J., Refiguring the Postclassical City. Dura Europos, Jerash, Jerusalem and Ravenna, Cambridge, 1995, pp. 86-94.

${ }_{87}$ Mango, C., Le développement..., p. 24.

${ }^{88}$ Eusebio Jerónimo, Chron. CCLXXVII Olymp. XXIIII: Dedicatur Constantinopolis omnium paene urbium nuditate.

89 Libanio, XIX, 19. Cf. Petit, P., "Les sénateurs de Constantinople dans l'oeuvre de Libanius", L'Antiquité Classique, 26 (1957), pp. 347-382; Wiemer, H. U., «Libanius on Constantine», Classical Quarterly, 
Si la fundación de Constantinopla era una empresa difícil desde el punto de vista económico y administrativo, no lo era menos desde el punto de vista jurídico. Constituir jurídicamente una Nueva Roma era imposible a efectos jurídicos. Para ello, Constantino se vio obligado a recurrir a un subterfugio jurídico: conceder a Constantinopla el lus Italicum ${ }^{90}$. En otras palabras, Constantino amplió el suelo itálico, no tanto con el fin de fundar una nueva ciudad cuanto de establecer una extensión de Roma en la Pars Orientis. El hecho de que Constantinopla recibiera el Ius Italicum y no el lus Romanum (del que era inalienable Roma) es muy significativo, pues revela que, desde el punto de vista jurídico, Constantinopla no fue sino una segunda Roma, que nunca podría aspirar a suplantar a la Roma Aeterna. En otras palabras, Constantinopla era Roma a efectos jurídicos, pero de ningún modo la primera Roma, pues sólo en virtud de la propia aeternitas de Roma Constantinopla había sido constituida como nueva capital del Imperio ${ }^{91}$. Es precisamente esta trasgresión de las normas de por sí, inamovibles, lo que permite explicar políticamente la fundación de Constantinopla, que no fue tanto una nueva capital del Imperio, sino una extensión de Roma en la Pars Orientis. Constantino convirtió así la reunificación del Imperio bajo su autoridad en una nueva empresa augustea, pero con una vocación todavía más amplia: el Imperio romano, con el traslado de las instituciones a la Pars Orientis, se había convertido en un Imperio universal, y Constantino había sido su autor político. En virtud de ello, las provincias orientales ya no estaban sometidas a Roma, pues el propio solar de Roma se encontraba en ellas.

\section{CONCLUSIONES}

Constantino fue un genio de la propaganda política. Era consciente de ello y aprovechó todo su ingenio para desarrollar su carrera política. Aunque inexplicablemente olvidada, su política de fundación de ciudades respondía a este propósito: transmitir a los ciudadanos un discurso político no a través de palabras o de imágenes, sino a través de una serie de disposiciones que, realmente, tenían escaso sentido administrativo, con la excepción de la fundación de la Ciuitas Tropaeensium, que se trataba de un enclave defensivo. Desde las diecinueve ciudades que recibieron sobrenombres honoríficos derivados del nombre del emperador, de sus familiares o de la familia imperial hasta la propia fundación de Constantinopla en calidad de Nueva Roma, casi todas las modificaciones de estatutos jurídicos de ciudades sancionadas por Constantino no respondían a otra razón que la de perpetuar su nombre unido al de las ciudades. No eran, sin embargo, de decisiones

44 (1994), pp. 511-524; Marasco, G., «La fondation de Constantinopla: éloge et psogos dans la tradition contemporaine", Suder, W. (ed.), Études de démographie du monde gréco-romain, Wroclaw, 2002, pp. 79-96; Moreno Resano, E., «La semblanza de Constantino en la obra de Libanio», Gerión, 24 (2006), pp. 341-353, esp. pp. 345-346.

90 Mazzarino, S., «La data dell'Oratio..., pp. 99-150.

91 Biscardi, A., "Constantinopolis nova Roma», Atti dell' Accademia Romanistica Costantiniana, II, Perugia, 1976, pp. 7-34, esp. pp. 24-29; Irmscher, J., «Neurom» oder «zweites Rom»-Renovatio oder Translatio», Klio, 65 (1983), pp. 431-439. 
carentes de sentido político, aunque fueran escasamente utilitarias: la concesión de un sobrenombre a una ciudad creaba vínculos de patronazgo entre el emperador y la ciudad, lo que reforzaba la lealtad debida por los ciudadanos al emperador. Mediante estas concesiones, el emperador se presentaba como conditor urbium y garante del ejercicio de la libertas política por parte de los ciudadanos. Este aspecto ideológico de la política de fundación de ciudades de Constantino, evocaba, ante todo, el ideario del principado civil de Augusto. De acuerdo con este discurso político subyacente a su política de fundaciones o concesión de sobrenombres a ciudades, Constantino se presentaba como el responsable de la devolución de la libertad política a los ciudadanos del Imperio, usurpada por los tiranos hasta el momento de su derrota. Y no era casual que Constantino se presentara como un restitutor libertatis cuando había desarrollado su política mediante la victoria militar sobre sus compañeros de Imperio, sistemáticamente presentados como tiranos.

Cuando en 324 Constantino logró la derrota de Licinio y todas las provincias del Imperio quedaron bajo su autoridad, la evocación del modelo político de Augusto quedó relegada por la imitatio Alexandri, esto es, la equiparación de las propias acciones de gobierno a las de Alejandro de Macedonia, que representaba el soberano conquistador ideal. Constantino fundó su ciudad, Constantinopla, de la que hizo una segunda capital del Imperio, al igual que Alejandro había fundado Alejandría. La fundación de Constantinopla sobre la antigua Bizancio no sólo recordaba la victoria de Constantino sobre Licinio, sino la adquisición por su parte de un Imperio universal. El nuevo Imperio de Constantino ya no era sólo un Imperio romano, sino un Imperio que comprendía todo el mundo civilizado, y que pretendía expandirse todavía más allá de sus fronteras. Esto explica el interés de Constantino por conceder sobrenombres honoríficos a ciudades de la lejana frontera arábigo-mesopotámica. De hecho, estas concesiones reflejaban la ambición de Constantino por representarse como conquistador de territorios para el Imperio, que, al igual que Alejandro, fundaba ciudades allí donde llegaban sus tropas. Desde luego, fue una política escasamente eficiente a efectos administrativos, ya que casi todas estas medidas afectaron a ciudades de pequeño tamaño, aunque no siempre, pero es cierto que refleja la ambición de Constantino por presentarse como fundador de un nuevo Imperio romano, después de haber terminado con la división del Imperio en distintas partes instituida por Diocleciano. Pero, sobre todo, tanto la simple concesión de sobrenombres como las fundaciones de ciudades propiamente dichas, garantizaban a Constantino la perennidad del recuerdo de su obra política, la renouatio Imperii, y con ella, hacían realidad la aeternitas de la basileía constantiniana ${ }^{92}$.

92 Piccinini, P., «Ideologia e storia in termini del lessico politico eusebiano: il tempo eterno della basileia di Costantino», Bonamente, G., y Fusco, F. (eds.), Costantino il Grande..., II, Macerata, 1993, pp. 769-790. 